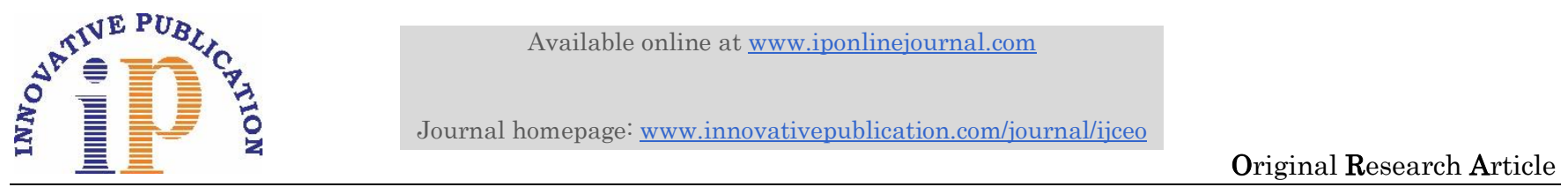

\title{
Prevalence of myopia in medical students
}

\author{
Rishi Mehta ${ }^{1 *}$, Nutan Bedi ${ }^{2}$, Sharda Punjabi ${ }^{3}$ \\ ${ }^{1-3}$ Associate Professor, Dept. of Ophthalmology, Geetanjali Medical College and Hospital, Udaipur, Rajasthan, India
}

\section{Article Info}

Received: $7^{\text {th }}$ February, 2019

Accepted: $3^{\text {rd }}$ June, 2019

Published Online: $9^{\text {th }}$ September, 2019

Keywords: Cycloplegic refraction, Myopia, Medical students, Near vision, Prevalence.

\begin{abstract}
Introduction: Myopia is a refractive error in which ability to see an object at a distance is reduced. Not only is this widely prevalent but also there has been an increase in the prevalence of myopia around the globe. Myopia leads to short-sightedness and sometimes irreversible blindness. Myopic patients have to use optical device like spectacles or contact lenses which have recurring expenses or undergo a laser refractive surgery which is very expensive. Pathological myopia if complicated by retinal detachement leads to immense morbidity and financial burden. Although many hypotheses have been proposed, but definite cause has not been established.

Materials and Methods: A cross-sectional study was conducted on medical students. Detailed history and eye examination was done. Uncorrected visual acuity, best corrected visual acuity, visual acuity by pin-hole, colour vision cycloplegic refraction, tonometry and fundus examination were performed. Intraocular pressure, keratometry and axial length measurements were done. Myopia was classified into low ( $-0.5 \mathrm{D}$ to 2.00D), moderate (-2.25D to $-6.00 \mathrm{D})$ and high $(>-6.00 \mathrm{D})$. Myopia prevalence was calculated and then statistically analyzed. $\mathrm{P}<0.05$ was considered statistically significant.

Results: Out of 233 (107 males) students myopia was found in (123) 52.78\%. Myopia was distributed in males and females as $54.47 \%$ vs. $45.52 \%$ ( $\mathrm{p}<0.05)$ respectively Low myopia, moderate myopia and high myopia were distributed as $61.78 \%, 26.82 \%$ and $11.38 \%$ among myopic students respectively. Low myopia was most common while high myopia was found to be least common.

Conclusion: Myopia was found to be highly prevalent in medical students. Greater time spent on near -work and indoor activities while lesser time on outdoor activities is a risk factor for myopia.
\end{abstract}

\section{Introduction}

Myopia is a type of refractive error in which parallel rays of light coming from infinity get focused in front of the retina rather than on the retina. ${ }^{1}$ In myopia ability to see distance objects is reduced while the ability to see near objects is maintained. So myopia is also known as short sightedness. ${ }^{2}$

Since myopia leads to inability to see the objects at a distance, it results in severe limitation of our day to day work which in turn leads to severe physical disability.

The severity of myopia is measured by the amount of power of the lens needed to focus the light rays further on to the retina. ${ }^{3}$

The patients suffering from myopia will have to use an optical device or undergo surgery to overcome this disability. The optical devices available are spectacles or contact lenses. These devices need to be changed regularly once a year or sometimes even earlier. It leads to recurring expenses. Another option for the treatment of myopia is surgery. Surgery can be either laser assisted refractive surgery or intraocular phakic lens implantation. ${ }^{4}$ These are immensely expensive procedures. This leads to increased cost of living of an individual and becomes an economic burden for the society as a whole. ${ }^{5}$

Myopia is of two types, simple myopia and pathological myopia. Simple myopia has been further classified into mild, moderate and high according to dioptric power required to correct myopia. While mild and moderate myopia lead to only a change in optical status of the eye, high myopia has been noted as a risk factor for structural complications like rhegmatogenous retinal detachment, muscae volitantes, posterior vitreous detachment, lattice degeneration and myopic maculopathy which in turn can result in irreversible blindness. ${ }^{6}$ Retinal detachment leads to loss of vision. It needs emergency surgery to restore vision. While the surgery is very expensive and not widely available, it leads to immense visual morbidity. Pathological myopia results in permanent structural changes in eye especially in macula, thereby causing permanent reduction in the visual acuity.

\footnotetext{
*Corresponding Author: Rishi Mehta, Associate Professor, Dept. of Ophthalmology, Geetanjali Medical College and Hospital, Udaipur, Rajasthan, India

Email: dr_rishimehta@yahoo.com

http://doi.org/10.18231/j.ijceo.2019.077
} 
Prevalence of myopia has been variable from place to place. Internationally, prevalence of myopia has been reported up to $80 \%$ from Hong Kong ${ }^{7}$ Taiwan, ${ }^{8}$ Singapore ${ }^{9}$ and Japan, ${ }^{10}$ while in Nigeria ${ }^{11}$ it was found to be only $18.3 \%$. In India prevalence of myopia has been found to be $30 \% .^{12}$

The cause of worry is not only the high prevalence of myopia, but also the rapid rise in past few years. ${ }^{13-15}$

While the exact cause of myopia has not been established, some hypotheses for prevalence of myopia have been put forth which encompasses environmental and genetic factors. The environmental factors include high education and economic prosperity but the most noteworthy association has been found to be an increase in the duration of near work. ${ }^{16-17}$

The students preparing for medical entrance examinations in India are forced to spent long hours every day in an attempt to get qualifying score. This can be one of the most important environmental factors affecting the prospective medical students. ${ }^{18}$

Since there is paucity of experimental and clinical data on the prevalence of myopia in India, we decided to conduct a study to get further insight in this ever increasing problem of high socio economic magnitude.

\section{Materials and Methods}

The cross-sectional study was done on medical students at American International Institute of Medical Sciences, Udaipur, India and Geetanjali Medical College and Hospital, Udaipur, India. The study was conducted on those students who were admitted in the year 2016. Each student was required to give written consent after detailed explanation regarding the study. Exclusion Criteria were previous history of trauma, glaucoma, cataract, eye surgery, atropine eye drop instillation for a prolonged time, Marfan's syndrome, Wagner Syndrome, Keratoconus and Stickler Syndrome.

Family history of myopia if present in the first degree and second degree relatives was entered.

Then the eye examination was performed. Distant visual acuity was recorded by Snellen's Chart. It was tested firstly without glasses, then with glasses and finally with pin hole. Color vision was assessed by Ischihara pseudo isochromatic color plates. Intra ocular pressure was checked by non- contact airpuff tonometre (Nidek Inc, Japan). Keratometry was done by Bausch and Lomb manual keratometre. Axial length was measured by A- scan ultrasound machine (Appasamy Inc, India). After vision assessment, the pupils were dilated. Dilatation was performed by instilling a mydriatic eye drop (Tropicamide Plus, Sunways Inc, India) which comprises of Tropicamide $0.5 \%$ and Phenylephrine 10\%. The mydriatic drop was instilled two times at an interval of 15 minutes. The pupil was checked for adequate mydriasis. Cycloplegic refraction by manual retinoscopy was performed after 30-40 minutes. We classified myopia in 3 different categories. Low myopia was classified as a refractive error of -0.5 to $-2.00 \mathrm{D}$, moderate myopia as a refractive error of -2.25 to $-6.00 \mathrm{D}$, and high myopia as a refractive error of $\geq-6.25 \mathrm{D}$. The data was entered in MS Excel 2013. Statically analysis was done by SPSS (version 20, Chicago IL). Statistical analysis for significance was done by Chi square test. $\mathrm{P}<0.05$ was considered statistically significant.

\section{Results}

A total of 250 medical students were enrolled for the study. Out of them, 17 students were excluded from the study. Of the 17 students who were excluded 12 had undergone refractive surgery, 1 had Marfan syndrome and 4 were using eye atropine eye drop. As a result 233 students adhered to our study criteria and were included in the study and were examined further. Out of a total number of 233 students examined, 107 (45.92\%) were males and $126(54.07 \%)$ were females. Out of the remaining 233 students who fulfilled the study criteria, myopia was found in 123 (52.78\%) students. The distribution of myopia in males and females has been shown in table 1 .

Table 1: Distribution of myopia among males and females $(\mathrm{n}=233)$

\begin{tabular}{|l|c|}
\hline Male & $56(24.03 \%)$ \\
\hline Female & $67(28.75 \%)$ \\
\hline Total & $123(52.78 \%)$ \\
\hline
\end{tabular}

Out of total 107 male students, myopia was found in 56 $(52.33 \%)$. Similarly out of 126 female students, myopia was found in $67(53.17 \%)$. This difference was not statistically significant $(\mathrm{p}>0.05)$.

Also among the total number of 123 students who were found to be myopic, $56(45.52 \%)$ were males and 67 $(52.73 \%)$ were females. This difference was also not statistically significant $(\mathrm{p}>0.05)$.

The amount of myopia was the basis for its classification in three different categories of low, moderate and high myopia. The various numbers of students suffering from myopia were further categorized as shown in table 2 .

Table 2: Distribution of Myopia according to severity $(\mathrm{n}=233)$

\begin{tabular}{|l|c|}
\hline Severity of Myopia (in dioptres) & Number of students \\
\hline Low (-0.5to -2.00$)$ & $76(32.61 \%)$ \\
\hline Moderate (-2.25 to -6.00$)$ & $33(14.16 \%)$ \\
\hline High $(\geq-6.25 \mathrm{D})$ & $14((6.00 \%)$ \\
\hline Total & $123(52.78 \%)$ \\
\hline
\end{tabular}

Out of a total of 123 myopic students low myopia, moderate myopia and high myopia was found in 76 (61.78\%), 33 (26.82\%) and $14(11.38 \%)$ respectively.

The most common type of myopia found in our study as mild myopia. High myopia was found to be the least common type.

Gender-wise distribution of myopia according to severity has been comprehensively shown graphically below. Low myopia was more common in females as compared to males. 
Among all the 56 males who were found to be myopic, $34(60.71 \%)$ were suffering from low myopia. Among all the 67 females who were found to be myopic, 42 (59.07\%) were suffering from low myopia. This difference was not statistically significant $(\mathrm{p}>0.05)$. Also the moderate myopia among males and females was $28.57 \%$ vs. $25.37 \%$; ( $>0.05)$. The high myopia among the males and females was found to be $10.71 \%$ vs. $11.94 \%$ ( $>>0.05)$.

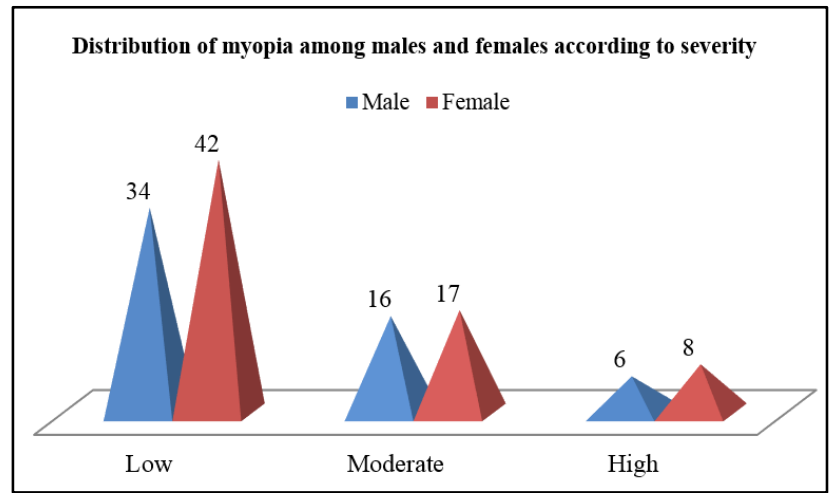

Fig. 1

\section{Discussion}

While the various refractive errors were known to be prevalent across the world in variable amounts, the myopia has stolen the limelight. The main reason for such a phenomenon has been the rapidity at which it has risen. Myopia has involved the entire spectrum of countries across the socioeconomic strata. From underdeveloped countries like Nigeria to developing countries like India to developed countries like Japan, all have been involved. ${ }^{19-21}$

While the prevalence has been rising rapidly, ironically the cause of myopia has remained obscure. Only some associations with myopia have been noted. Myopia has been noted in children spending the most of their time in-doors and also those children with lack of outdoor activities. ${ }^{22}$ But the duration of near -work has been more strongly associated with myopia. ${ }^{23}$

In our study which was conducted on the medical students at a medical college, we found $52.78 \%$ as myopic (Table 1). There are some studies which have been conducted across the world but they have reported huge variations in their results.

Myopia has been found to be as high as $87.5 \%$ in Hong Kong $^{24}$ to $82 \%$ in Singapore. ${ }^{25}$ But the most noteworthy has been Taiwan where prevalence was found to be $92.8 \%$ which had increased to $95.8 \%$ over a short time of just five years. ${ }^{26}$ Highlighting the magnitude of variability, a prevalence of only $57.6 \%$ was found in Lahore ${ }^{27}$ and $50.3 \%$ in Norway. ${ }^{28}$ Interestingly, in Norway it was noted that the prevalence of myopia at the age of 20 years was just $43.3 \% .^{29}$ This in effect meant that the prevalence of myopia only increases over a period of time. This can also be assumed to be a result of increasing the amount of near work as the age progresses.

That the near work is a probable risk factor is further highlighted by the fact that prevalence of myopia has been very low in school children. A low prevalence rate of $6.97 \%$ was found in Punjab ${ }^{30}$ and $4.74 \%$ in Srinagar. ${ }^{31}$

Also in Hong Kong, it has been found that the prevalence of myopia was 30\% at ages 6-7 years, which increased to $70 \%$ at ages $16-17$ years. ${ }^{32}$ Similarly in Finland, prevalence has risen from less than $10 \%$ in early $20^{\text {th }}$ century to a high of $30 \%$ in late $20^{\text {th }}$ century. ${ }^{33}$

Ironically, a study conducted in school children in Rajasthan has reported the prevalence of myopia to as high as $56.9 \% .^{34}$

The variability in prevalence rates of myopia across the globe can be attributed to three factors. Firstly, the diverse cultural, and socio- economic background of the populations involved Secondly, the method of conducting the study which includes the differences in the methods of sampling and the lack of clarity of definition and categorization of myopia. Thirdly, the method of performing retinoscopy along with the difference in cycloplegic drugs used to achieve cycloplegia. In our study we have used tropicamide $0.5 \%$ to achieve cycloplegia. But other studies have used homatropine, cyclopentolate or atropine to achieve cycloplegia. ${ }^{27-29,31-37}$

As far as the distribution of myopia according to gender is concerned, increased prevalence was found in female medical students as compared to males (Table 1). In our study $54.47 \%$ females were suffering from myopia as against only $45.52 \%$ males. There has been a general social condition in India in which girls usually stay indoors and avoid outdoor sports. Also girls are seen to be more sincere in their studies which translate in to higher number of time spent on studies.

In India, the competitive examination for admission to medical colleges is very tough. Among several lakhs of candidates appearing for the examination, only a few thousands are selected. As a result the students have to prepare for the examination by spending several hours every day.

Since more amount of time is spent on books, thereby more amount of time is spent on focusing the near objects. This is achieved by a special status of refraction in eye by contraction of crystalline lens. This contraction of lens is known as accommodation. Prolonged accommodation can lead to permanent structural changes in eye like increase in the axial length. This may in turn lead to axial myopia. Thereby it gives prudence to the hypothesis that near work does play a role in myopia.

Contrary to the other studies conducted in which high myopia was found to be $20 \%$ to $40 \%^{20,38}$ we found high myopia only in $6 \%$ of medical students (Table 2). This could be attributed to higher educational level among students, better awareness and thereby enabling to access earlier medical help.

The limitation of our study is small sample size, short study duration, and lack of follow up of the students. So a more detailed study on a large number of students for a longer duration along with their follow up is recommended.

Source of Funding: None. 


\section{Conflict of Interest: None.}

\section{References}

1. Curtin B. Topics to be considered when establishing standards for clinical myopia studies. Acta Ophthalmol Suppl. 1988;185:61-2.

2. Curtin BJ. The myopias: basic science and clinical management. Philadelphia, PA: Harper and Row, 1985.

3. Kempen JH, Mitchell P, Lee KE. The prevalence of refractive errors among adults in the United States, Western Europe, and Australia. Arch Ophthalmol. 2004;122(4):495-5.

4. Angle J, Wissmann DA. The epidemiology of myopia. Am J Epidemiol. 1980;111(2):220-8.

5. Lin LK, Shih YF, Tsai CB. Epidemiologic study of ocular refraction among school children in Taiwan in 1995. Optom Vis Sci. 1999;76:275-81.

6. Hsu WM, Cheng CY, Liu JH. Prevalence and causes of visual impairment in an elderly Chinese population in Taiwan: the Shihpai Eye Study. Ophthalmol. 2004;111(1):62-9.

7. Burton TC. The influence of refractive errors and lattice degeneration on the incidence of RD. Trans Am Ophthalmol Soc. 1990:143-55.

8. Lam CSY, Goh WSH. The incidence of refractive errors among school children in Hong Kong and its relationship with the optical components. Clin Exp Optom. 1991;74:97-103.

9. Tan NWH, Saw SM, Lam DSC. Temporal variations in myopia progression in Singaporean children within an academic year. Optom Vis Sci. 2000;77:465-72.

10. Edwards MH. The development of myopia in Hong Kong children between the ages of 7 and 12 years: A five-year longitudinal study. Ophthal Physiol Opt. 1999;19:286-94.

11. Yap M, Wu M, Wang SH. Environmental factors and refractive error in Chinese schoolchildren. Clin Exp Optom. 1993b;77:8-14.

12. Lin LLK, Tsai CB, Lieu JC. Correlation between ocular refractions with longitudinal study among schoolchildren in Taiwan. In: Tokoro T, editor. Myopia Updates: Proceedings of the 6th International Conference on Myopia. Springer-Verlag; Tokyo: 1998. pp. 53-7.

13. Lam CSY, Edwards MH. Myopia: Prevalence and risk factors. Optician. 1999;217:28-31.

14. Wu HM, Seet B, Yap EPH. Does education explain ethnic differences in myopia prevalence? A population-based study of young adult males in Singapore. Optom Vis Sci. 2001;78(4):234-9.

15. Wong TY, Foster PJ, Hee J. Prevalence and risk factors for refractive errors in adult Chinese in Singapore. Invest Ophthalmol Vis Sci. 2000;41:2486-94.

16. Ezelum C, Razavi H, Sivasubramaniam S. Refractive error in Nigerian adults: prevalence, type, and spectacle coverage. Invest Ophthalmol Vis Sci. 2011;52(8):5449-56.

17. Raju P, Ramesh SV, Arvind H. Prevalence of refractive errors in a rural South Indian population. Invest Opthalmol Vis Sci. 2004;45(12):4268-72.

18. Zhao JL, Pan XJ, Sui RF. Refractive error study in children: Results from Shunyi district, China. Am J Ophthalmol. 2000;129:427-35.

19. Midelfart A, Kinge B, Midelfart S. Prevalence of refractive errors in young and middle-aged adults in Norway. Acta Ophthalmol Scand. 2006;80:501-5.

20. Lin LLK, Shih YF, Hsiao CK. Prevalence of myopia in Taiwanese schoolchildren: 1993 to 2005. Ann Acad Med Singapore. 2005;33:27-33.

21. Guggenheim JA, Hill C, Yam TF. Myopia, genetics, and ambient lighting at night in a UK sample. Br J Ophthalmol. 2007;87:580-2.

22. Midelfart A, Aamo B, Sjöhaug KA. Myopia among medical students in Norway. Acta Ophthalmol Scand. 2007;70:317-22.
23. Loman J, Quinn GE, Kamoun L. 2002. Darkness and near work. Myopia and its progression in third - year law students. Ophthalmol. 2009;109:1032-8.

24. Seet B, Wong TY, Tan DT. Myopia in Singapore: taking a public health approach. Br J Ophthalmol. 2007;85:521-6.

25. Chua WH, Saw SM, Wu HM. Refractive errors in schoolchildren: theSingapore Myopia Cohort Study. In: Thorn F, Troilo D, Gwiazda J, editors. Proceedings of the VIII International Conference on Myopia; 2006 July 7 - 9; Boston, United States. United States: Conference on Myopia, 2006:11.

26. W W Woo, K A Lim, H Yang. Refractive errors in medical students in Singapore. Singapore Med J. 2004;45(10):470-4.

27. Lin (Lin, L.K., Shih, Y.F., Lee, Y.C., Hung, P.T., and Hou, P.K. Changes in ocular refraction and its components among medical students - a 5-year longitudinal study. Optom Vis Sci. 1996;73:495-8.

28. Goh and Lam (Goh, W.S., Lam, C.S. Changes in refractive trends and optical components of Hong Kong Chinese aged 19 39 years. Ophthal Physiol Opt. 1994;14:378-82.

29. Ojaimi E, Rose KA, Morgan IG. Distribution of ocular biometric parameters and refraction in a population - based study of Australian children. Invest Ophthalmol Vis Sci. 2007;46:2748-54.

30. Chaudhry R, Ali H, Sheikh NH. Frequency and underlying factors of myopia among medical students. Biomedica 2011;27:154-60..

31. Lam C.S, Goh W.S. The incidence of refractive errors among schoolchildren in Hong Kong in relationship with the optical components. Clin Exp Optom. 1991;74:97-103.

32. Refractive errors -a review from Punjab-NPCB India. 2007;1(4).

33. Ishfaq Ahmed, Seema Mian, Syed Mudasir. Prevalence of myopia in students of srinagar city of Kashmir, India. Int $J$ Health Sci (Qassim). 2008;2(1):77-81.

34. Sotiris Plaini, Joanna Moschandreas, Panagoula Nikolitsa. Myopia and visual acuity impairment: A comparative study of Greek and Bulgarian school children. Ophthal Physiol Opt. 2009;29:312-20.

35. Pärssinen $\mathrm{O}$. The increased prevalence of myopia in Finland. Acta Phthalmol. 2012;90(6):497-502.

36. Chanchal Shrivastav, Suman Sharma, Suman Jain. Prevalence of refractive errors among school children in western Rajasthan. Int J Curr Res. 2013;5(10):2907-8.

37. Y-H Guo, H-Y Lin, L L K Lin. Self-reported myopia in Taiwan: 2005 Taiwan National Health Interview Survey. Eye. 2012;26:684-9.

38. Holden BA, Fricke TR, Wilson DA. Global prevalence of myopia and high myopia and temporal trends from 2000 through 2050. Ophthalmol. 2016;123:1036-42.

How to cite this article: Mehta R, Bedi N, Punjabi S. Prevalence of myopia in medical students. Indian J Clin Exp Ophthalmol 2019;5(3):322-5. 